\title{
Outcomes of growing rods in a series of early-onset scoliosis patients with neurofibromatosis type 1
}

\author{
Charlie Bouthors, MD, Ruben Dukan, MD, Christophe Glorion, MD, PhD, and Lotfi Miladi, MD \\ Pediatric Orthopedic Surgery Department, Hôpital Necker Enfants Malades, Assistance Publique Hôpitaux de Paris, France
}

\begin{abstract}
OBJECTIVE Early-onset scoliosis (EOS) is not uncommon in patients with neurofibromatosis type 1 (NF1). Despite conservative treatment, spinal deformities progress and require early surgical intervention. To avoid potential interference with chest and trunk growth, growing rods (GRs) have been used effectively in EOS of various etiologies. In this study the authors sought to analyze the outcomes of GRs in EOS patients with NF1.
\end{abstract}

METHODS This was a retrospective single-center cohort study that included consecutive EOS patients with NF1 who were treated with GRs and were followed up for a minimum of 2 years. Clinical and radiological analyses were performed preoperatively and until the last follow-up.

RESULTS From to 2008 to 2017, 18 patients ( 6 male, 12 female) underwent GR surgery (14 single GRs, 4 dual GRs) at a mean age of $8 \pm 2.1$ years. Mean follow-up was $5 \pm 2.4$ years. Fifty-five lengthenings were performed at a mean rate of 3 lengthenings per patient (range $0-7)$. Ten of 14 single GRs (71\%) were converted into dual GRs during treatment. No patient underwent definitive posterior spinal fusion (PSF) at GR treatment completion. The mean initial and last follow-up major curves were $57^{\circ}$ and $36^{\circ}$, respectively ( $p<0.001,37 \%$ correction). The average T1-S1 increase was $13 \mathrm{~mm} / \mathrm{yr}$. Six of 9 hyperkyphotic patients had normal kyphosis at last follow-up. There were 26 complications involving 13 patients (72\%), with 1 patient who required unplanned revision. The primary complications were instrumentation related, consisting of 17 proximal hook dislodgments, 6 distal pedicle screw pullouts, and 2 rod fractures. Only 1 patient experienced a mechanical complication after dual GR implantation. There were no wound infections.

CONCLUSIONS The GR technique provided satisfactory spinal deformity control in EOS patients with NF1 while allowing substantial spinal growth. Adequately contoured dual GRs with proximal hooks placed in nondystrophic regions should be used to minimize implant-related complications. Surgeons should not attempt to correct kyphosis at GR implantation.

https://thejns.org/doi/abs/10.3171/2020.2.SPINE191308

KEYWORDS type 1 neurofibromatosis; early-onset scoliosis; spine deformity; growing rod; fusionless surgery; dystrophic scoliosis

$\mathrm{N}$ EUROFIBROMATOSIs type 1 (NF1) is an autosomal dominant genetic disease with a worldwide incidence of approximately 1 per $2500-3000$ individuals. Scoliosis is the most frequent musculoskeletal manifestation in NF1. Localized neurofibromas, primary mesodermal dysplasia, osteomalacia, and endocrine disturbances may be the etiologies for the development of spinal imbalance in NF1. ${ }^{1-3}$

NF1 spinal deformity is generally classified into 2 types, nondystrophic and dystrophic, based on evidence of skeletal dystrophy on imaging. Nondystrophic types have clinical and radiological features similar to those of idio- pathic scoliosis and can be treated similarly, with comparable responses to treatment. ${ }^{2}$ Dystrophic features consist of rib penciling or spindling of the transverse processes, vertebral scalloping, wedging of one or more vertebral bodies, paraspinal or intraspinal soft tissue masses, and a short curve with significant apical rotation that may lead to subluxed or dislocated vertebral bodies, foraminal enlargement, and defective pedicles. ${ }^{4}$ Curve progression is common, especially in patients younger than 7 years and those exhibiting $\geq 3$ dystrophic features. ${ }^{5,6}$ Dystrophic curves should be treated without a prior observation period because they always progress. 7,8

ABBREVIATIONS AP = anteroposterior; EOS = early-onset scoliosis; GR = growing rod; NF1 = neurofibromatosis type 1 ; PJA = proximal junctional angle; PJK = proximal junctional kyphosis; PSF = posterior spinal fusion.

SUBMITTED October 31, 2019. ACCEPTED February 18, 2020.

INCLUDE WHEN CITING Published online April 24, 2020; DOI: 10.3171/2020.2.SPINE191308. 
Spinal deformities can manifest early in NF1 patients, usually between the ages of 5 and 8 years. ${ }^{9}$ This timeframe corresponds with that of early-onset scoliosis (EOS), in which spine deformity develops before the age of 10 years. Treatment of EOS patients is particularly challenging since spinal growth maintenance is critical for pulmonary maturation and function. ${ }^{10}$ Although primary spinal fusion has been the mainstay of NF1 spinal deformities, it is not appropriate in EOS because it results in a short spine and chest as well as lung underdevelopment. ${ }^{11}$

Among various growth-friendly techniques, growing rods (GRs) have been proven to be effective in controlling spine deformity while promoting trunk growth. ${ }^{12,13}$ However, few studies have evaluated the outcomes of GRs in EOS patients with NF1.14-16

The primary objective of this study was to analyze the outcomes of GRs in EOS patients with NF1.

\section{Methods \\ Patients}

A retrospective study was conducted in a single pediatric treatment center. Ethics approval was obtained from the local institutional review board. All EOS patients with NF1 treated with GRs and at least 2 years of follow-up were included consecutively. Patients were operated on by 3 experienced pediatric spine surgeons. When required, the diagnosis of NF1 was made by pediatricians and geneticists using establishing diagnostic criteria and genetic testing. Surgical indications were scoliotic curve with a major curve Cobb angle of $>50^{\circ}$ (Figs. 1 and 2), documented scoliosis progression despite bracing, or scoliosis with thoracic hyperkyphosis $\left(>40^{\circ}\right)$.

\section{Preoperative Treatment}

Bracing was attempted in all patients before surgical management unless surgical criteria were already met. Traction films were obtained to assess curve flexibility and reducibility. Patients with a severe and rigid curve underwent preoperative preparation specific to their case with either a turnbuckle cast or halo gravity traction for 4-6 weeks in order to progressively correct the deformity.

\section{Surgical Management}

Spinal instrumentation used was either CD Legacy (Medtronic) or E-Spine (Euros). Each construct consisted of either single or dual 5.5 titanium rods attached to the spine with proximal hooks forming pediculolaminar claws and distal monoaxial pedicle screws ${ }^{17}$ (Figs. 3 and 4). In the beginning of our experience, an anterior convex epiphysiodesis was performed systematically in patients with dystrophic curves. This procedure was later abandoned, as we noticed that posterior spine stabilization with a solid GR construct would provide satisfactory correction. Patients were reviewed in the clinic every 6-9 months after the original procedure. Deformity was monitored clinically and radiologically. Distraction procedures were performed "on demand" according to deformity progression, at an interval that ensured spinal growth. The lengthening program was discontinued once deformity demonstrated no signs of progression.

\section{Clinical Evaluation}

Medical records of all patients were reviewed. Clinical information included sex, age at GR insertion, length of follow-up, and complications. Surgical data consisted of the GR construct used, fixation levels, number of distractions, implant failure, and revision.

\section{Radiological Evaluation}

Radiographic parameters were measured on standing anteroposterior (AP) and lateral whole-spine radiographs using the PACS software Carestream Vuemotion (Carestream Health). Analyses were repeated prior to GR insertion, immediately after GR insertion, and at the last follow-up. AP view measurements included the major curve angle defined according to the Cobb method ${ }^{18}$ and the trunk length (T1-S1 distance). Lateral view measurements included thoracic kyphosis (T4-T12) and proximal junctional kyphosis (PJK). PJK was defined as a proximal junctional angle (PJA) greater than $10^{\circ}$ or at least greater than the preoperative measurement. ${ }^{19}$ Skeletal maturity was defined as Risser stage 4 on radiographic studies.

A full-spine MRI was obtained preoperatively for analysis of components of the deformity and intraspinal contents in order to reveal the presence of intracanal anomalies that might interfere with surgical deformity correction.

\section{Statistical Analysis}

Qualitative variables are reported as mean $\pm \mathrm{SD}$ (range) and quantitative variables as $\mathrm{n}(\%)$. Comparisons between preoperative, postoperative, and last follow-up measurements were analyzed using the Wilcoxon signed-rank test, and $\mathrm{p}$ values $<0.05$ were considered significant. All analyses were performed with the $\mathrm{R}$ statistical environment R3.4.2 (R core team, https://www.r-project.org/).

\section{Results \\ Cohort}

From 2008 to 2017, 20 EOS patients with NF1 underwent GR surgery in our institution. Two patients with incomplete data (missing radiographic studies) were excluded. Thus, 18 patients ( 6 male, 12 female) were included in the study, with a mean age of $8 \pm 2.1$ years (range $4-12$ years) at GR implantation (Table 1). The mean follow-up was $5 \pm 2.4$ years (range $2-10$ years). There were 17 patients with a thoracic curve and 1 with a lumbar curve. All spinal deformities had dystrophic features. Preoperative MRI revealed dural ectasia in 2 patients and spinal neurofibroma in 6 patients.

\section{Surgery}

Before GR surgery, 13 patients (72\%) underwent a specific preparation (5 with halo gravity traction, 8 with turnbuckle cast). An anterior convex epiphysiodesis was performed in 5 patients (28\%) (Table 1). At initial surgery, 14 single GRs and 4 dual GRs were implanted. The mean number of instrumented segments was $12 \pm 2$ (range 9-18). Fifty-five lengthenings were performed, with an average of 3 lengthenings per patient (range $0-7$ ). The average lengthening interval was $18 \pm 7$ months (range 8-30 


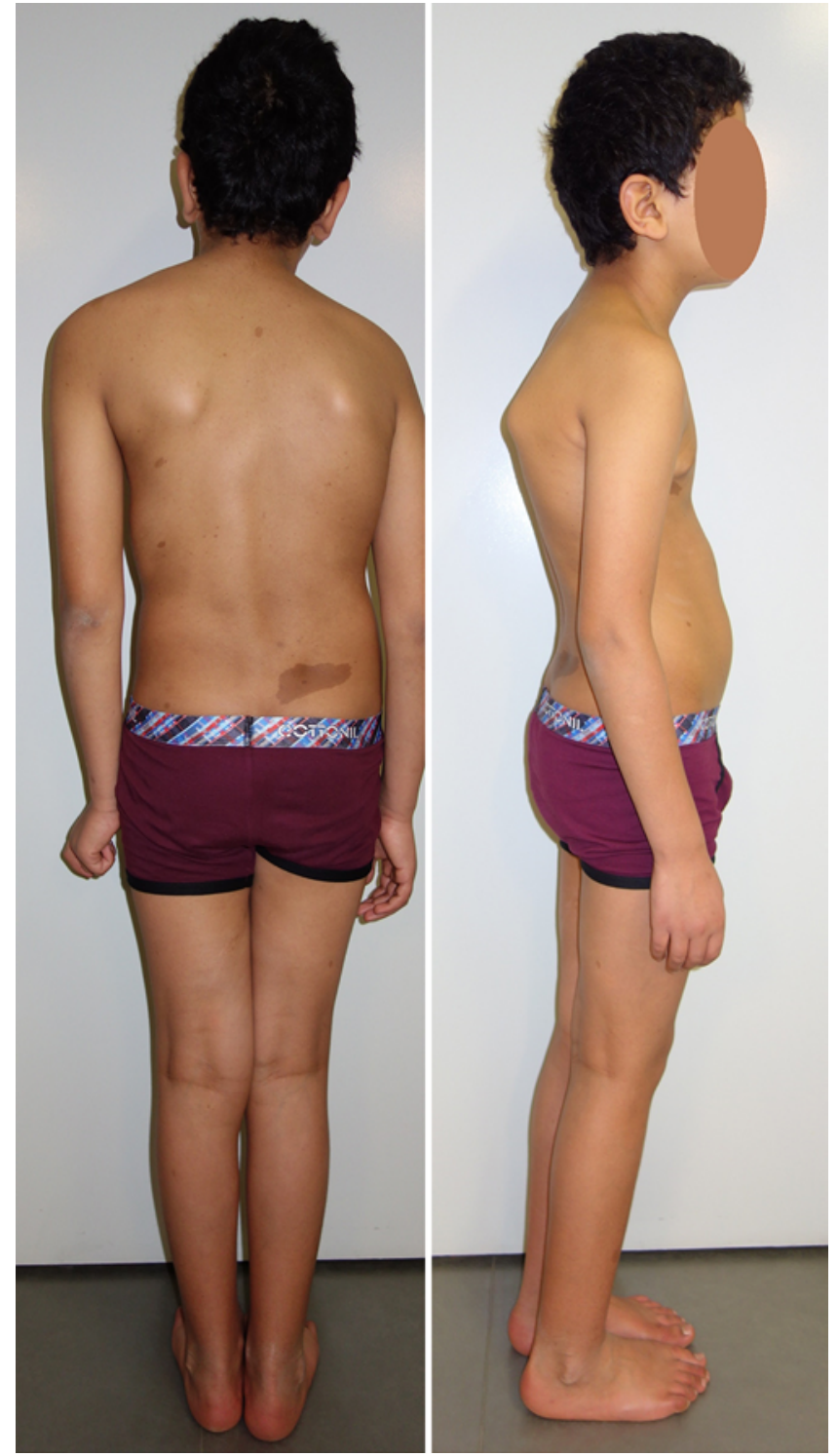

FIG. 1. Posteroanterior and lateral photographs of patient 10 (male, age 8 years) prior to GR insertion. Figure is available in color online only.

months). In 10 of 14 patients (71\%), single GRs were converted into dual GRs at a mean of $5 \pm 2$ years (range 2-9 years) after the initial surgery, and no further distraction was required thereafter. Among these patients, 4 were still skeletally immature. Six patients $(33 \%)$ were skeletally mature at final follow-up. No patient underwent definitive posterior spinal fusion (PSF) at GR treatment completion.

\section{Radiological Evaluation}

\section{Major Coronal Curve}

The preoperative major curve Cobb angle averaged $57^{\circ}$ $\pm 15^{\circ}$ (range $31^{\circ}-90^{\circ}$ ). After GR implantation, coronal deformity was reduced to an average of $36 \pm 14^{\circ}$ (range $\left.9^{\circ}-68^{\circ}, \mathrm{p}<0.001\right)$. The amount of initial correction was $37 \%$ (range 10\%-70\%). At final follow-up, the major curve averaged $37 \pm 13^{\circ}$ (range $18^{\circ}-67^{\circ}, \mathrm{p}<0.001$ ), corresponding to $35 \%$ correction.

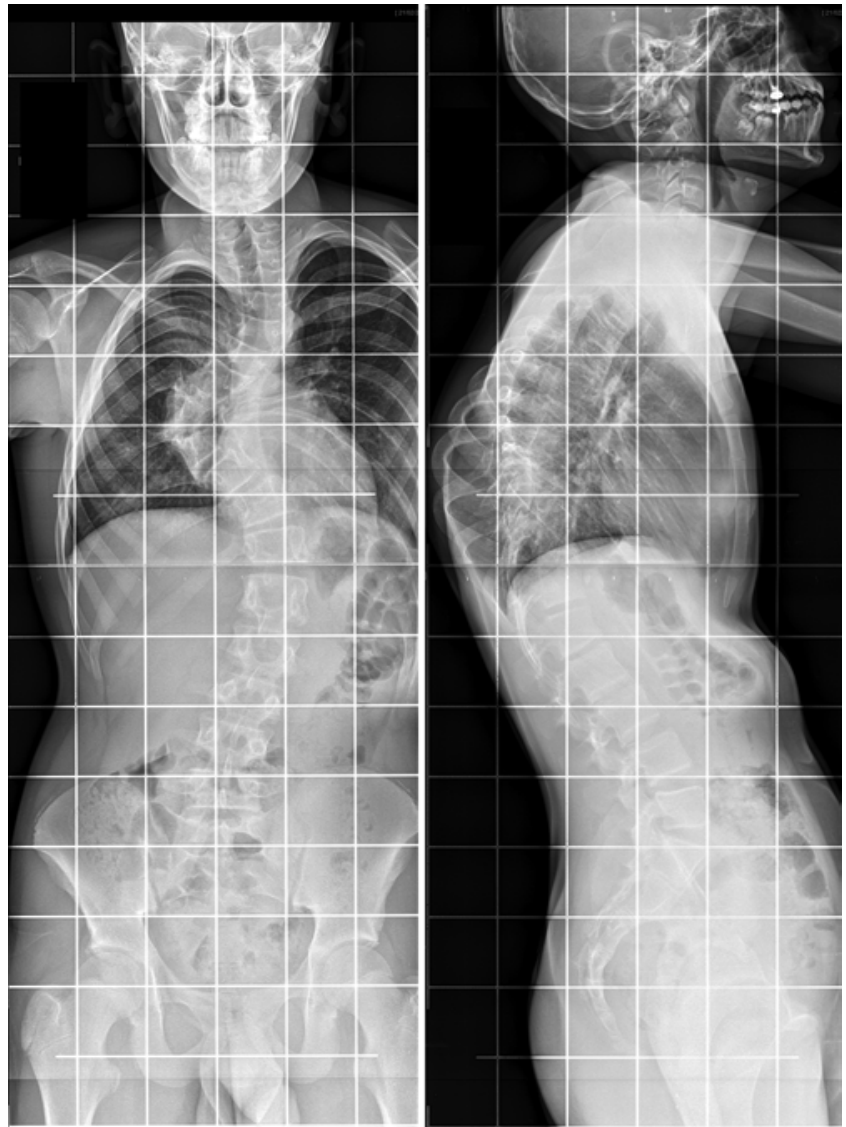

FIG. 2. AP and lateral radiographs of patient 10 (male, age 8 years) prior to GR insertion.

At the last follow-up, deterioration in Cobb angle was reported in 1 patient (patient 2 in Table 1).

\section{Thoracic Kyphosis}

Preoperative thoracic kyphosis (T4-T12) averaged $37^{\circ}$ $\pm 19^{\circ}\left(\right.$ range $11^{\circ}-79^{\circ}$ ), and 9 patients $(50 \%)$ were hyperkyphotic. Mean thoracic kyphosis was $31^{\circ} \pm 12^{\circ}$ (range $8^{\circ}-54^{\circ}$ ) after GR implantation and remained stable at $34^{\circ}$ $\pm 11^{\circ}$ (range $17^{\circ}-54^{\circ}$ ) at last follow-up. Six of 9 hyperkyphotic patients had normal kyphosis at the last follow-up, and 1 patient (patient 7) with normal preoperative thoracic kyphosis developed hyperkyphosis postoperatively.

\section{Trunk Length}

T1-S1 length increased from a mean of $307 \mathrm{~mm}$ (range $216-371 \mathrm{~mm}$ ) preoperatively to $328 \pm 47 \mathrm{~mm}$ (range 238$397 \mathrm{~mm})$ after the initial procedure $(\mathrm{p}<0.001)$ and 367 $\pm 59 \mathrm{~mm}$ (range 265-444 mm) at the last follow-up (p < 0.001 ). The T1-S1 growth averaged $60 \pm 30 \mathrm{~mm}$ (range 4-116 mm) per patient at a mean rate of $13 \pm 6 \mathrm{~mm}$ per year (range 1.8-24 mm).

\section{Complications}

There were 26 complications involving 13 patients (72\%) (Table 2). Only 1 complication led to an unplanned surgery. Intraoperatively, there were 2 dural tears that 


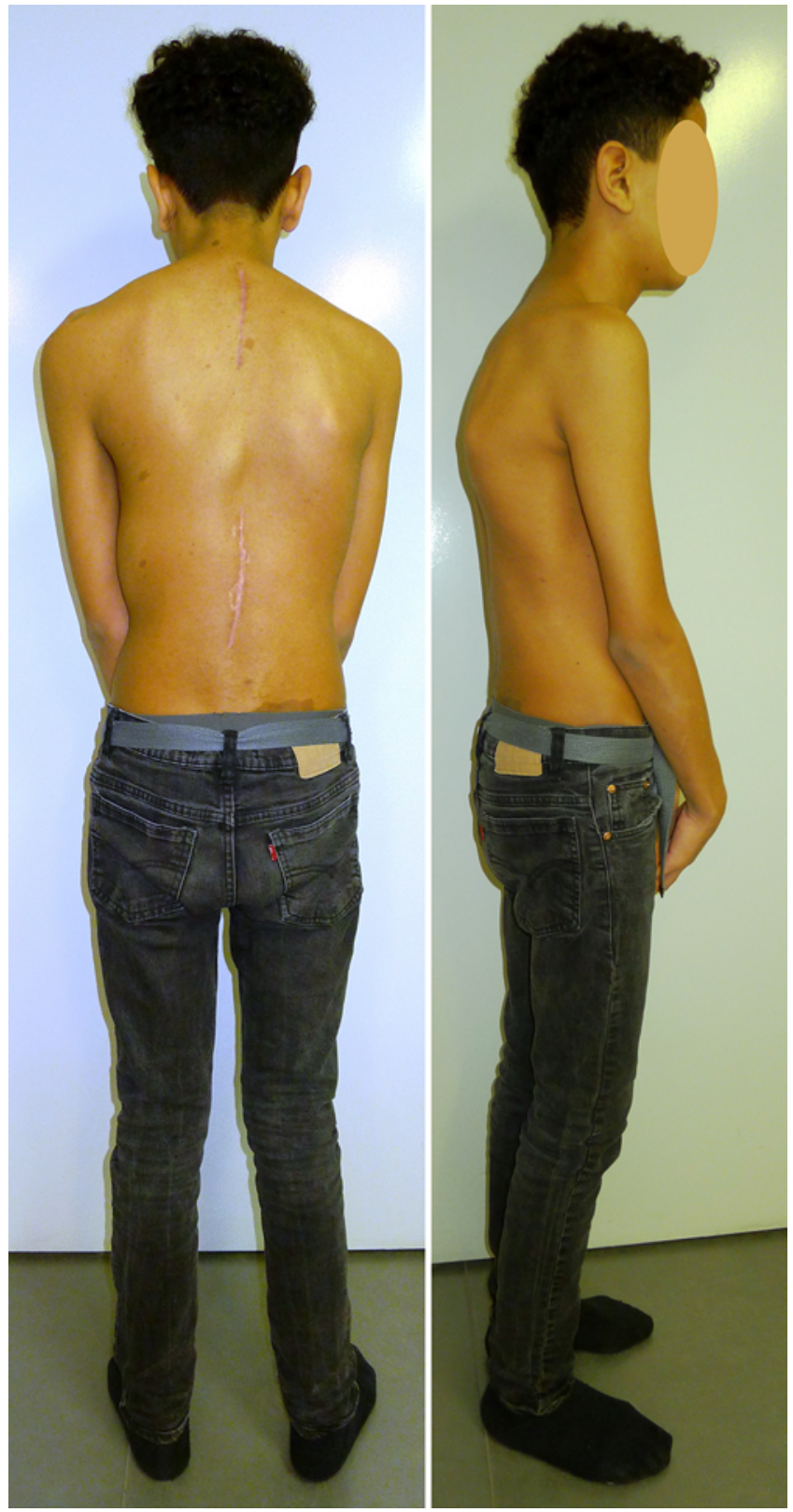

FIG. 3. Posteroanterior and lateral views of patient 10 (male, age 14 years) at last follow-up. Figure is available in color online only.

occurred during revision surgery for proximal fixation of the construct in the cervical region. Implant-related complications included 9 proximal hook dislodgments, 6 distal screw pullouts, and 2 broken rods (single GR). Proximal hook dislodgments were revised to extend the fixation levels higher up and/or add a second GR (Fig. 5). Most of these patients were hyperkyphotic preoperatively. Alignment-related complications consisted of 2 proximal adding-ons, 2 distal adding-ons, 1 deteriorating scoliotic curve, 1 deteriorating kyphosis, and 1 PJK that developed within 3 years following GR insertion and was revised with cephalad fixation extended up to $\mathrm{C} 2$ and arthrodesis of the cervical region. The single unplanned surgery occurred a week after the initial surgery to reposition the

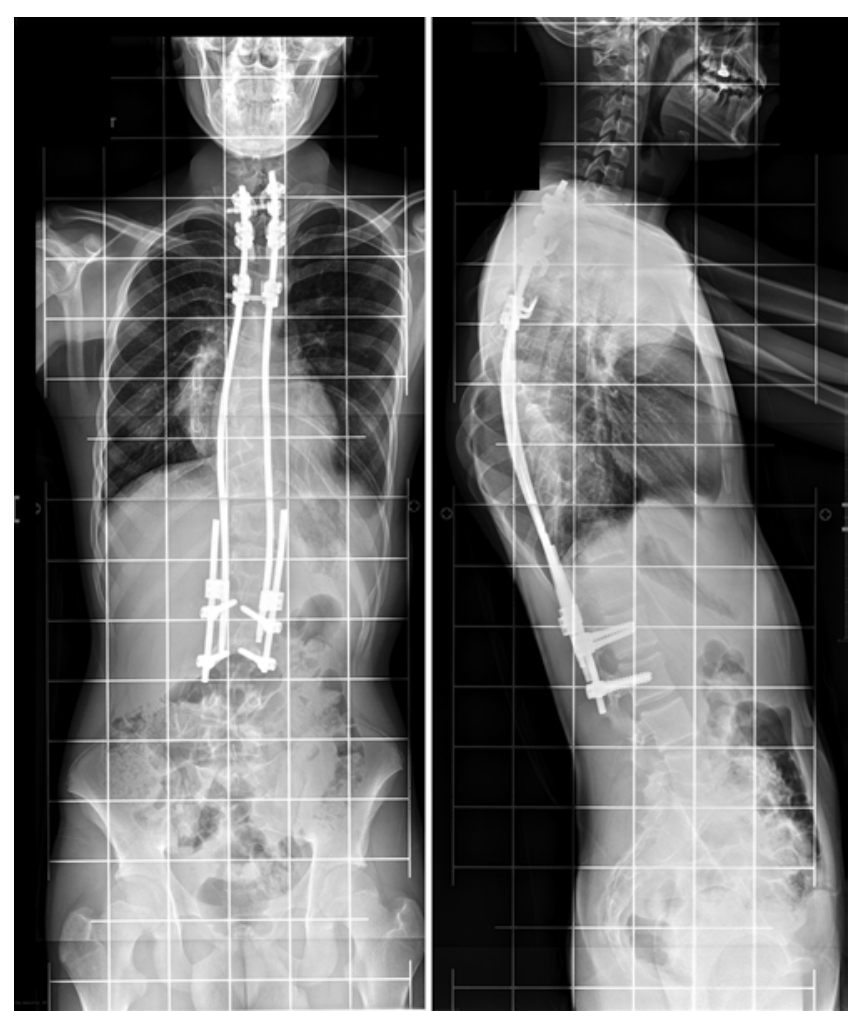

FIG. 4. AP and lateral radiographs of patient 10 (male, age 14 years) at last follow-up.

distal pedicle screws that pulled out. No infections occurred in this series.

\section{Discussion}

The GR technique has been used successfully in the treatment of EOS of different etiologies. However, its use in NF1 patients is still controversial. In this retrospective case series, the outcomes of GRs in 18 EOS patients with at least 2 years of follow-up were assessed. Despite a high implant-related complication rate, satisfactory deformity control and spinal growth were achieved in this cohort.

Overall, there was a $35 \%$ correction of the major curve Cobb angle at the last follow-up. Only 1 patient deteriorated throughout treatment. Recent studies on GRs for EOS patients with NF1 reported coronal correction ranging from $38.6 \%$ to $51 \% .^{14,15,20}$ We corrected the coronal plane at initial surgery and it was maintained throughout the lengthening program, as described previously by Cheung et al. ${ }^{13}$ We noticed that once instrumented, most curves were mildly progressive and thus required distraction infrequently. For the sagittal plane, instrumentation being in place for several years induces posterior spine epiphysiodesis, ${ }^{21,22}$ which may lead to progressive kyphosis correction over time. Some other studies have reported satisfactory sagittal correction with GRs even in cases of hyperkyphosis. ${ }^{23,24} \mathrm{Rib}$-based distraction may not be suitable in NF1. Chen et al. compared GRs and rib-based distraction (with a vertical expandable prosthetic titanium rib [VEPTR]) in deformity correction. Despite similar spinal 
TABLE 1. Clinical and radiological characteristics of 18 EOS patients with NF1 who underwent GR treatment

\begin{tabular}{|c|c|c|c|c|c|c|c|c|c|c|c|c|c|}
\hline \multirow[b]{2}{*}{$\begin{array}{l}\text { Pt } \\
\text { No./ } \\
\text { Sex }\end{array}$} & \multirow[b]{2}{*}{$\begin{array}{l}\text { FU } \\
\text { (yrs) }\end{array}$} & \multirow[b]{2}{*}{$\begin{array}{c}\text { Spinal } \\
\text { Neurofibroma }\end{array}$} & \multirow[b]{2}{*}{$\begin{array}{l}\text { Dural } \\
\text { Ectasia }\end{array}$} & \multirow[b]{2}{*}{$\begin{array}{l}\text { Age } \\
\text { at } \\
\text { Index } \\
\text { Op } \\
\text { (yrs) }\end{array}$} & \multirow[b]{2}{*}{$\begin{array}{c}\text { Preop } \\
\text { Preparation }\end{array}$} & \multirow[b]{2}{*}{$\begin{array}{c}\text { Ant Convex } \\
\text { Epiphysiodesis }\end{array}$} & \multirow[b]{2}{*}{$\begin{array}{l}\text { Initial GR } \\
\text { Construct }\end{array}$} & \multirow[b]{2}{*}{$\begin{array}{c}\text { Fixation } \\
\text { Level } \\
(\mathrm{GR})\end{array}$} & \multicolumn{2}{|c|}{ Preop } & \multicolumn{2}{|c|}{ Last FU } & \multirow[b]{2}{*}{$\begin{array}{l}\text { T1-S1 } \\
\text { Length } \\
\text { Increase } \\
(\mathrm{mm})\end{array}$} \\
\hline & & & & & & & & & $\begin{array}{c}\text { Major } \\
\text { Curve } \\
\text { Cobb } \\
\text { Angle } \\
\left({ }^{\circ}\right)\end{array}$ & $\begin{array}{c}\text { Thoracic } \\
\text { Kyphosis } \\
\left({ }^{\circ}\right)\end{array}$ & $\begin{array}{c}\text { Major } \\
\text { Curve } \\
\text { Cobb } \\
\text { Angle } \\
\left(^{\circ}\right)\end{array}$ & $\begin{array}{c}\text { Thoracic } \\
\text { Kyphosis } \\
\left({ }^{\circ}\right)\end{array}$ & \\
\hline $1 / \mathrm{M}$ & 10 & + & No & 8 & - & + & Single & T3-L2 & 46 & 21 & 18 & 34 & 77 \\
\hline $2 / M$ & 9 & - & No & 8 & - & + & Single & T5-L2 & 31 & 17 & 42 & 37 & 54 \\
\hline $3 / \mathrm{M}$ & 9 & - & No & 6 & Turnbuckle cast & + & Single & $\mathrm{T} 1-\mathrm{L} 1$ & 45 & 14 & 22 & 17 & 116 \\
\hline $4 / F$ & 3 & + & Yes & 7 & Turnbuckle cast & + & Single & T2-L2 & 60 & 11 & 40 & 18 & 49 \\
\hline $5 / F$ & 6 & + & No & 11 & $\begin{array}{l}\text { Halo gravity } \\
\text { traction }\end{array}$ & - & Single & C7-L2 & 63 & 48 & 53 & 31 & 105 \\
\hline $6 / M$ & 7 & - & No & 8 & - & - & Single & T3-L2 & 72 & 79 & 36 & 49 & 65 \\
\hline $7 / F$ & 2 & + & No & 8 & Turnbuckle cast & + & Single & T1-L1 & 90 & 26 & 44 & 46 & 12 \\
\hline $8 / F$ & 4 & - & No & 5 & $\begin{array}{l}\text { Halo gravity } \\
\text { traction }\end{array}$ & - & Single & T1-L3 & 78 & 45 & 67 & 23 & 21 \\
\hline 9/F & 6 & - & No & 9 & Turnbuckle cast & - & Single & $\mathrm{T} 1-\mathrm{L} 1$ & 38 & 27 & 26 & 24 & 79 \\
\hline 10/M & 2 & - & No & 8 & Turnbuckle cast & - & Single & T2-L3 & 60 & 26 & 39 & 28 & 73 \\
\hline $11 / F$ & 5 & + & No & 12 & $\begin{array}{l}\text { Halo gravity } \\
\text { traction }\end{array}$ & - & Single & C5-L4 & 76 & 66 & 55 & 45 & 4 \\
\hline $12 / F$ & 5 & - & Yes & 12 & Turnbuckle cast & - & Single & T3-L4 & 67 & 47 & 19 & 35 & 88 \\
\hline $13 / M$ & 5 & - & No & 8 & $\begin{array}{l}\text { Halo gravity } \\
\text { traction }\end{array}$ & - & Dual & C6-L1 & 57 & 44 & 36 & 54 & 60 \\
\hline $14 / F$ & 4 & + & No & 4 & $\begin{array}{l}\text { Halo gravity } \\
\text { traction }\end{array}$ & - & Dual & C7-L1 & 52 & 26 & 23 & 29 & 55 \\
\hline $15 / F$ & 4 & - & No & 8 & Turnbuckle cast & - & Single & T1-L1 & 57 & 18 & 41 & 39 & 79 \\
\hline $16 / F$ & 3 & - & No & 7 & - & - & Single & T2-L2 & 54 & 50 & 45 & 28 & 60 \\
\hline $17 / F$ & 2 & - & No & 10 & Turnbuckle cast & - & Dual & T2-L2 & 38 & 54 & 29 & 36 & 25 \\
\hline $18 / F$ & 2 & - & No & 9 & - & - & Dual & T2-L2 & 47 & 48 & 31 & 31 & 49 \\
\hline
\end{tabular}

ant = anterior; FU = follow-up; pt = patient; + = present; - = absent.

growth and coronal correction, these authors found better sagittal correction with GRs (44\% vs $23 \%$, p < 0.001). ${ }^{25}$ Also, we do recommend rib fixation since ribs are very fragile in this condition, even if they are not dystrophic.

Anterior convex epiphysiodesis was performed only at the beginning of our experience. This procedure was later abandoned for 2 reasons. First, excision of plexiform neurofibroma may cause massive hemorrhage. ${ }^{26,27}$ Second, we noticed that sufficient correction and stability was provided with a posterior dual GR construct combined with sequential lengthening. None of these patients required anterior grafting during follow-up. Some authors have advocated AP spinal fusion in cases with rigid hyperkyphosis exceeding $50^{\circ} .5,28$ Tauchi et al. reported excellent correction (frontal 66\%, sagittal 32\%) with circumferential fusion among 11 EOS patients with NF1 $1{ }^{29}$ However, most cases required thoracic surgeon assistance, and on average patients needed 1.5 surgeries for additional bone grafting for augmentation because of pressure erosion from enlarging neurofibromas and dural ectasia. Posterior-only fusion is not recommended due to the risk of the crankshaft phenomenon..$^{30,31}$

There was an unusually long distraction interval in this cohort; however, the T1-S1 increase of $13 \mathrm{~mm}$ per year was similar to that for healthy immature spines ${ }^{10}$ and deformity correction was satisfactory. We have noticed that as opposed to infantile or "syndromic" curves, dystrophic curves are mildly progressive once instrumented. Carbone et al. reported a 1-year distraction interval in their cohort of NF1 patients. ${ }^{14}$ Also, kyphotic forms do not require numerous distractions since posterior autofusion will help correct kyphosis progressively. Another reason for the long distraction interval used in this cohort was that the risk of wound infection is minimized by reducing the frequency of distraction. ${ }^{14}$

Single GRs were implanted initially because we feared that dual GRs would cause more autofusion. Cahill et al. ${ }^{21}$ suggested that local disturbance of perispinal structures by GRs might cause spontaneous autofusion. Dual GRs were used subsequently when studies reported higher risks of rod fracture ${ }^{32,33}$ and other implant-related complications ${ }^{34}$ with single GRs. Other studies have shown better deformity correction and maintenance, both sagittal and coronal, with dual GRs compared with single GRs. ${ }^{35}$ In our study, most single GRs (71\%) were converted into dual GRs following mechanical complications (Fig. 5). 
TABLE 2. Complication incidence and relation to characteristics of the 18 EOS patients who underwent GR treatment

\begin{tabular}{cc}
\hline \multicolumn{1}{c}{ Characteristic } & No. $(\%)$ \\
\hline Cohort size & 18 \\
\hline$\geq 1$ complication & $13(72)$ \\
\hline Unplanned op & $1(6)$ \\
\hline Total complications & 26 \\
\hline Intraoperative & 2 \\
\hline Dural tear & 2 \\
\hline Implant related & 17 \\
\hline Proximal hook dislodgment & 9 \\
\hline Pedicle screw pullout & 6 \\
\hline Rod fracture & 2 \\
\hline Alignment related & 7 \\
\hline Proximal junctional kyphosis & 1 \\
\hline Loss of sagittal correction of primary deformity & 1 \\
\hline Loss of coronal correction of primary deformity & 1 \\
\hline Proximal adding-on & 2 \\
\hline Distal adding-on & 2 \\
\hline
\end{tabular}

No complications occurred thereafter except in 1 patient whose construct was extended for implant dislodgment.

None of our skeletally mature patients (33\%) underwent a definitive PSF at GR treatment completion, for the following 2 reasons. First, NF1 makes it difficult to complete bony union after surgery, ${ }^{9,36}$ with a rate of pseudarthrosis ranging from $15 \%$ to $31 \%{ }^{9,36,37}$ Second, spinal ankylosis is likely to develop throughout the lengthening program..$^{21,22,38,39}$ When posterior stabilization was followed by a solid construct, we noticed a progressive improvement in spinal bone quality in dystrophic areas and bone formation around GRs on radiological images. Some authors have suggested that PSF could be avoided in cases of satisfactory alignment and trunk height at skeletal maturity. Jain et al..$^{40}$ analyzed 167 EOS patients treated with GRs who had reached skeletal maturity and had their most recent surgery a minimum of 2 years earlier. Radiological outcomes of 30 patients who retained the GRs without fusion (observation group) were compared to those of 137 patients who underwent a definitive fusion (final surgical fusion group). At mean times from initial surgery of 5.7 years in the observation group and 8.9 years in the final surgical fusion group $(p=0.122)$, Jain et al. found no statistical difference between the patient without and those with fusion in the final curve magnitude $\left(41^{\circ}\right.$ and $46^{\circ}$, respectively, $\mathrm{p}=0.182$ ) and increase in mean trunk length $(30.5 \%$ and $35 \%$, respectively, $\mathrm{p}=0.142)$. Further studies with longer follow-ups are required to determine whether retaining GRs in NF1 patients is a biomechanically viable solution to avoid PSF.

With $72 \%$ of patients in our study experiencing complications, this rate was higher than the rates found in other series on GRs used with other etiologies (i.e., idiopathic, neuromuscular, etc.). ${ }^{32,41}$ However, only one complication in our study required an unplanned surgery. The most frequent complication was implant related (65\%), namely
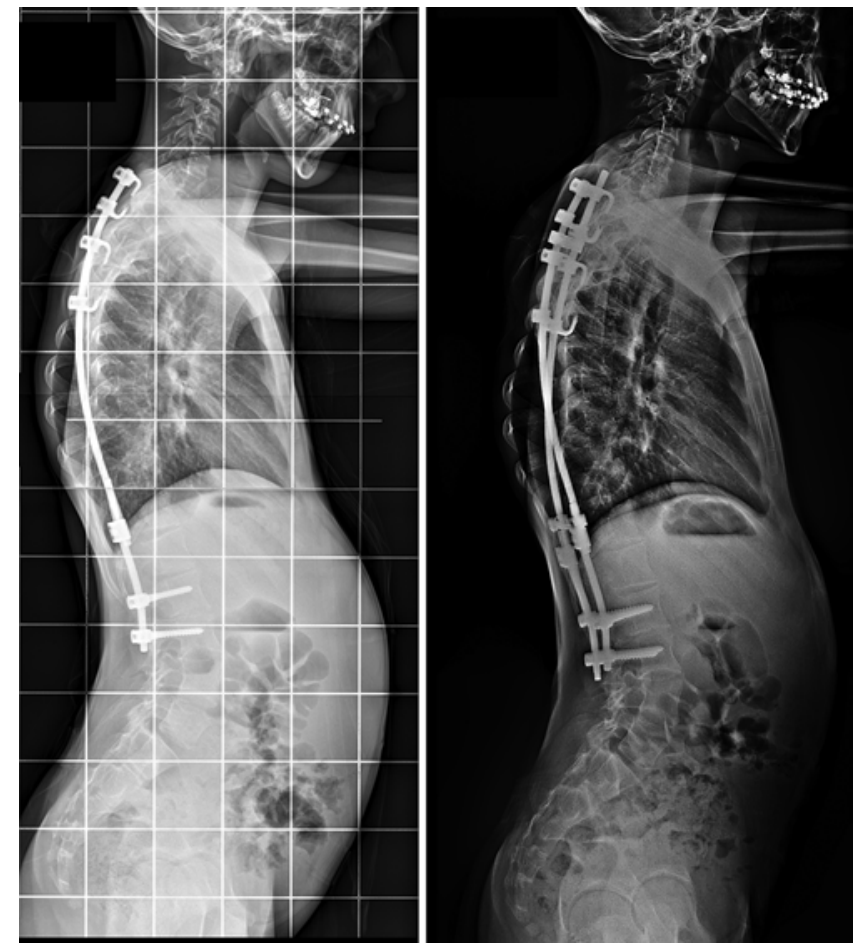

FIG. 5. Left: Lateral radiograph showing dislodgment of cephalad hooks. Right: Right lateral radiograph after addition of second rod (dual GRs).

proximal hook dislodgment (Table 2). This complication, which occurred as a gradual phenomenon due to laminae stretching, unlike the acute pullout observed with pedicle screws, was diagnosed on follow-up radiographs and was usually asymptomatic. Therefore, it was addressed during scheduled lengthening. Yao et al. ${ }^{20}$ compared early definitive fusion $(n=32)$ with GR techniques $(n=27)$ in NF1 patients. Identified risk factors of instrumentation-related complications were kyphosis $>50^{\circ}(\mathrm{OR} 8.23, \mathrm{p}=0.025)$ and use of GRs (OR 8.75, $\mathrm{p}=0.032)$. Jain et al..$^{15}$ reported $57 \%$ implant-related complications in their series of NF1 patients treated with GRs. Dystrophic bone, ${ }^{42}$ osteopenia, ${ }^{43}$ and short-segmented curvature with kyphosis ${ }^{36,44,45}$ may be the leading causes of GR complications in NF1 patients. Certainly, the use of single GRs with upper thoracic spine fixation was another reason in our study (Fig. 5). To reduce this risk, we recommend: 1) use of a dual GR construct; 2) fixation points in a nondystrophic area (frequently in the cervical region); 3) proximal hooks instead of pedicle screws; 4) 2 to 3 pairs of distal pedicle screws; 5) adequate rod contouring, particularly in the proximal part, to reduce mechanical stress imparted on laminae and implants; and 6) no attempt to correct kyphosis at initial surgery (a gradual correction will occur over time).

The variability in treatment modalities seen in this study is explained by the evolution of our experience with GRs. Currently, we perform early dual GR surgery for every dystrophic deformity. In advanced cases in which early surgery was not performed, patients undergo preoperative preparation by halo gravity traction. The anterior approach is no longer performed since satisfactory progressive cor- 
rection is obtained through "on demand" distraction of a solid dual GR construct.

\section{Study Limitations}

This study has several limitations. Selection bias and confounding may exist in association with its retrospective nature. Functional and health-related quality of life outcomes were not assessed, and there was no control group that included patients treated with primary spine fusion. This study does not define management of patients at GR treatment completion. A study with a larger sample size and longer follow-up is required to analyze the effectiveness and late complications of GRs.

\section{Conclusions}

The GR technique provided excellent spinal deformity control in EOS patients with NF1 while allowing substantial spinal growth. Pediatric spine surgeons must be prepared to manage implant-related complications. To limit the risk of complications, it is recommended to use adequately contoured dual GRs with proximal hooks. Surgeons should not attempt to correct kyphosis at GR implantation because it will occur gradually throughout a lengthening program. Further studies with longer follow-up are required to define the best approach at GR treatment completion (definitive fusion vs retaining GRs without fusion).

\section{References}

1. Chaglassian JH, Riseborough EJ, Hall JE. Neurofibromatous scoliosis. Natural history and results of treatment in thirtyseven cases. J Bone Joint Surg Am. 1976;58(5):695-702.

2. Crawford AH, Parikh S, Schorry EK, Von Stein D. The immature spine in type-1 neurofibromatosis. J Bone Joint Surg Am. 2007;89(suppl 1):123-142.

3. Funasaki H, Winter RB, Lonstein JB, Denis F. Pathophysiology of spinal deformities in neurofibromatosis. An analysis of seventy-one patients who had curves associated with dystrophic changes. J Bone Joint Surg Am. 1994;76(5):692700 .

4. Crawford AH. Neurofibromatosis in the pediatric patient. Orthop Clin North Am. 1978;9(1):11-23.

5. Calvert PT, Edgar MA, Webb PJ. Scoliosis in neurofibromatosis. The natural history with and without operation. $J$ Bone Joint Surg Br. 1989;71(2):246-251.

6. Durrani AA, Crawford AH, Chouhdry SN, et al. Modulation of spinal deformities in patients with neurofibromatosis type 1. Spine (Phila Pa 1976). 2000;25(1):69-75.

7. Savini R, Parisini P, Cervellati S, Gualdrini G. Surgical treatment of vertebral deformities in neurofibromatosis. Ital $J$ Orthop Traumatol. 1983;9(1):13-24.

8. Winter RB, Moe JH, Bradford DS, et al. Spine deformity in neurofibromatosis. A review of one hundred and two patients. J Bone Joint Surg Am. 1979;61(5):677-694.

9. Crawford AH. Pitfalls of spinal deformities associated with neurofibromatosis in children. Clin Orthop Relat Res. 1989;(245):29-42.

10. Dimeglio A, Canavese F. The growing spine: how spinal deformities influence normal spine and thoracic cage growth. Eur Spine J. 2012;21(1):64-70.

11. Goldberg CJ, Gillic I, Connaughton O, et al. Respiratory function and cosmesis at maturity in infantile-onset scoliosis. Spine (Phila Pa 1976). 2003;28(20):2397-2406.

12. Bouthors C, Izatt MT, Adam CJ, et al. Minimizing spine autofusion with the use of semiconstrained growing rods for early onset scoliosis in children. J Pediatr Orthop. 2018;38(10):e562-e571.

13. Cheung JPY, Yiu K, Kwan K, Cheung KMC. Mean 6-year follow-up of magnetically controlled growing rod patients with early onset scoliosis: a glimpse of what happens to graduates. Neurosurgery. 2019;84(5):1112-1123.

14. Carbone M, Vittoria F, Del Sal A. Treatment of early-onset scoliosis with growing rods in patients with neurofibromatosis-1. J Pediatr Orthop B. 2019;28(3):278-287.

15. Jain VV, Berry CA, Crawford $\mathrm{AH}$, et al. Growing rods are an effective fusionless method of controlling early-onset scoliosis associated with neurofibromatosis type 1 (NF1): a multicenter retrospective case series. J Pediatr Orthop. 2017;37(8):e612-e618.

16. Yao Z, Guo D, Li H, et al. Surgical treatment of dystrophic scoliosis in neurofibromatosis type 1: outcomes and complications. Clin Spine Surg. 2019;32(1):E50-E55.

17. Miladi L, Mousny M. A novel technique for treatment of progressive scoliosis in young children using a 3-hook and 2-screw construct $(\mathrm{H} 3 \mathrm{~S} 2)$ on a single sub-muscular growing rod: surgical technique. Eur Spine J. 2014;23(suppl 4):S432S437.

18. Cobb JR. Outline for the study of scoliosis. In: Instructional Course Lectures. Vol. 5. American Academy of Orthopedic Surgeons; 1948:261-275.

19. Watanabe K, Uno K, Suzuki T, et al. Risk factors for proximal junctional kyphosis associated with dual-rod growingrod surgery for early-onset scoliosis. Clin Spine Surg. 2016;29(8):E428-E433.

20. Yao Z, Li H, Zhang X, et al. Incidence and risk factors for instrumentation-related complications after scoliosis surgery in pediatric patients with NF-1. Spine (Phila Pa 1976). 2018;43(24):1719-1724.

21. Cahill PJ, Marvil S, Cuddihy L, et al. Autofusion in the immature spine treated with growing rods. Spine (Phila Pa 1976). 2010;35(22):E1199-E1203.

22. Sankar WN, Skaggs DL, Yazici M, et al. Lengthening of dual growing rods and the law of diminishing returns. Spine (Phila Pa 1976). 2011;36(10):806-809.

23. Atici Y, Akman YE, Erdogan S, et al. The effect of growing rod lengthening technique on the sagittal spinal and the spinopelvic parameters. Eur Spine J. 2015;24(6):1148-1157.

24. Chen Z, Qiu Y, Zhu Z, et al. How does hyperkyphotic earlyonset scoliosis respond to growing rod treatment? J Pediatr Orthop. 2017;37(8):e593-e598.

25. Chen Z, Li S, Qiu Y, et al. Evolution of the postoperative sagittal spinal profile in early-onset scoliosis: is there a difference between rib-based and spine-based growth-friendly instrumentation? J Neurosurg Pediatr. 2017;20(6):561-566.

26. Kitano D, Osaki T, Nakasone M, et al. Two cases of debulking surgery for lower limb diffuse plexiform neurofibroma with transcatheter arterial embolisation. Int J Surg Case Rep. 2019;55:132-135.

27. Mukherji MM. Giant neurofibroma of the head and neck. Plast Reconstr Surg. 1974;53(2):184-189.

28. Parisini P, Di Silvestre M, Greggi T, et al. Surgical correction of dystrophic spinal curves in neurofibromatosis. A review of 56 patients. Spine (Phila Pa 1976). 1999;24(21):2247-2253.

29. Tauchi R, Kawakami N, Castro MA, et al. Long-term surgical outcomes after early definitive spinal fusion for early-onset scoliosis with neurofibromatosis type 1 at mean follow-up of 14 years. J Pediatr Orthop. 2020;40(1):42-47.

30. Canavese F, Dimeglio A, Volpatti D, et al. Dorsal arthrodesis of thoracic spine and effects on thorax growth in prepubertal New Zealand white rabbits. Spine (Phila Pa 1976). 2007;32(16):E443-E450.

31. Greggi T, Martikos K. Surgical treatment of early onset scoliosis in neurofibromatosis. Stud Health Technol Inform. 2012;176:330-333. 
32. Bess S, Akbarnia BA, Thompson GH, et al. Complications of growing-rod treatment for early-onset scoliosis: analysis of one hundred and forty patients. J Bone Joint Surg Am. 2010;92(15):2533-2543.

33. Yang JS, Sponseller PD, Thompson GH, et al. Growing rod fractures: risk factors and opportunities for prevention. Spine (Phila Pa 1976). 2011;36(20):1639-1644.

34. Choi E, Yazsay B, Mundis G, et al. Implant complications after magnetically controlled growing rods for early onset scoliosis: a multicenter retrospective review. J Pediatr Orthop. 2017;37(8):e588-e592.

35. Thompson GH, Akbarnia BA, Kostial P, et al. Comparison of single and dual growing rod techniques followed through definitive surgery: a preliminary study. Spine (Phila Pa 1976). 2005;30(18):2039-2044.

36. Sirois JL III, Drennan JC. Dystrophic spinal deformity in neurofibromatosis. J Pediatr Orthop. 1990;10(4):522-526.

37. Halmai V, Domán I, de Jonge T, Illés T. Surgical treatment of spinal deformities associated with neurofibromatosis type 1. Report of 12 cases. J Neurosurg. 2002;97(3)(suppl):310-316.

38. Agarwal A, Goswami A, Vijayaraghavan GP, et al. Quantitative characteristics of consecutive lengthening episodes in early-onset scoliosis (EOS) patients with dual growth rods. Spine (Phila Pa 1976). 2019;44(6):397-403.

39. Noordeen HM, Shah SA, Elsebaie HB, et al. In vivo distraction force and length measurements of growing rods: which factors influence the ability to lengthen? [erratum in: Spine (Phila Pa 1976). 2012;37(5):432]. Spine (Phila Pa 1976). 2011;36(26):2299-2303.

40. Jain A, Sponseller PD, Flynn JM, et al. Avoidance of "final" surgical fusion after growing-rod treatment for early-onset scoliosis. J Bone Joint Surg Am. 2016;98(13):1073-1078.

41. Kwan KYH, Alanay A, Yazici M, et al. Unplanned reoperations in magnetically controlled growing rod surgery for early onset scoliosis with a minimum of two-year follow-up. Spine (Phila Pa 1976). 2017;42(24):E1410-E1414.
42. Prudhomme L, Delleci C, Trimouille A, et al. Severe thoracic and spinal bone abnormalities in neurofibromatosis type 1 [published online November 26, 2019]. Eur J Med Genet. doi:10.1016/j.ejmg.2019.103815

43. Lodish MB, Dagalakis U, Sinaii N, et al. Bone mineral density in children and young adults with neurofibromatosis type 1. Endocr Relat Cancer. 2012;19(6):817-825.

44. Akbarnia BA, Gabriel KR, Beckman E, Chalk D. Prevalence of scoliosis in neurofibromatosis. Spine (Phila Pa 1976). 1992;17(8)(suppl):S244-S248.

45. Holt RT, Johnson JR. Cotrel-Dubousset instrumentation in neurofibromatosis spine curves. A preliminary report. Clin Orthop Relat Res. 1989;(245):19-23.

\section{Disclosures}

The authors report no conflict of interest concerning the materials or methods used in this study or the findings specified in this paper.

\section{Author Contributions}

Conception and design: Bouthors, Miladi. Acquisition of data: Bouthors, Dukan, Miladi. Analysis and interpretation of data: Bouthors, Glorion, Miladi. Drafting the article: Bouthors. Critically revising the article: Bouthors, Glorion, Miladi.

Reviewed submitted version of manuscript: Bouthors, Miladi. Approved the final version of the manuscript on behalf of all authors: Bouthors. Study supervision: Miladi.

\section{Correspondence}

Charlie Bouthors: Hôpital Necker Enfants Malades, Paris, France. charlie.bouthors@hotmail.fr. 